\title{
PEMODELAN ATMOSFER DENGAN WRF PADA KEJADIAN BANJIR JAKARTA 17 JANUARI 2013
}

\author{
Ardhi Adhary Arbain ${ }^{1}$, Mahally Kudsy ${ }^{2}$, M. Djazim Syaifullah ${ }^{3}$
}

\begin{abstract}
Intisari
Simulasi WRF pada tanggal 16-17 Januari 2013 dilakukan untuk menguji performa model dalam mendeteksi fenomena seruak dingin dan hujan ekstrim yang merupakan pemicu utama bencana banjir Jakarta pada periode tersebut. Metode verifikasi kualitatif dan kuantitatif pada tiap grid secara dikotomi digunakan untuk membandingkan keluaran model dengan data observasi Global Satellite Mapping of Precipitation (GSMaP) dan NCEP Reanalysis. Performa model WRF dihitung berdasarkan nilai akurasi (ACC), Critical Success Index (CSI), Probability of Detection (POD) dan False Alarm Ratio (FAR) yang diperoleh dari hasil verifikasi numerik. Hasil pengujian menunjukkan bahwa WRF mampu melakukan deteksi waktu awal kejadian hujan ekstrim dengan tepat setelah 6-7 jam sejak inisiasi model dilakukan. Performa terbaik WRF teramati pada pukul 02-09 WIB (LT) dengan nilai CSI mencapai 0,32, POD 0,82 dan FAR 0,66. Hasil verifikasi secara kualitatif dan kuantitatif juga menunjukkan bahwa WRF dapat melakukan deteksi seruak dingin dan hujan ekstrim sebelum banjir terjadi, walaupun dengan ketepatan durasi waktu dan lokasi kejadian yang masih relatif rendah bila dibandingkan dengan data observasi.
\end{abstract}

\begin{abstract}
WRF simulation on January 16-17, 2013 has been conducted to evaluate the model performance in detecting cold surge and extreme precipitation phenomena which were the triggers of Jakarta flood event during the period. Qualitative and quantitative dichotomous grid-to-grid verification methods are utilized to compare the model output with Global Satellite Mapping of Precipitation (GSMaP) observation and NCEP Reanalysis dataset. WRF model performance is calculated based on the scores of accuracy (ACC), Critical Success Index (CSI), Probability of Detection (POD) and False Alarm Ration (FAR) which are generated from numerical verification. The results show that WRF could precisely detect the onset of extreme precipitation event in 6-7 hours after the model initiation. The best performance of the model is observed at 02-09 WIB (LT) with CSI score of 0.32, POD 0.82 and FAR 0.66. Despite the model inability to accurately predict the duration and location of cold surge and extreme precipitation, the qualitative and quantitative verification results also show that WRF could detect the phenomena just before the flood event occured.
\end{abstract}

Kata kunci : WRF, model, banjir, seruak dingin, hujan ekstrim

\section{PENDAHULUAN}

Kejadian hujan ekstrim dan banjir pada pertengahan bulan Januari 2013 tercatat sebagai salah satu bencana alam terburuk dalam sejarah Jakarta. Hujan lebat yang terjadi secara berulang di wilayah Jawa bagian barat dan sekitarnya sejak tanggal 15-18 Januari 2013, mencapai puncaknya pada tanggal 17 Januari 2013, dengan curah hujan mencapai lebih dari $100 \mathrm{~mm}$ per sehari (Wu et al,
2013). Kerugian yang diakibatkan oleh kejadian hujan ekstrim yang dipicu oleh Asian Winter Monsoon Cold Surge atau yang lazim disebut seruak dingin (Chang et al, 2005) diperparah karena belum tersedianya sistem peringatan dini yang cukup akurat dalam memprediksi fenomena cuaca tersebut. Pada studi ini, kami melakukan simulasi pemodelan atmosfer dengan menggunakan model prediksi cuaca numerik Weather Research and Forcasting (WRF) beberapa saat sebelum kejadian 
banjir Jakarta terjadi, dan membandingkan hasilnya dengan data observasi pada periode yang sama, baik secara kualitatif maupun kuantitatif (numerik).

WRF adalah model prediksi cuaca yang telah dikenal luas dan banyak digunakan dalam berbagai studi atmosfer maupun untuk keperluan prediksi cuaca operasional di seluruh dunia. Salah satu kelebihan WRF adalah aplikasinya yang sangat fleksibel dan efisien pada berbagai platform sistem, mulai dari super computer yang rumit dan masif hingga laptop yang sederhana dan mudah digunakan (Skamarock et al, 2008). Namun seperti halnya model numerik yang lain, aplikasi WRF di daerah tropis seperti benua maritim Indonesia masih memberikan tantangan tersendiri karena sistem cuaca yang kompleks pada wilayah tersebut. Beberapa studi prediksi cuaca dengan model numerik, seperti MM5 (Salimun et al, 2010; Sow et al, 2010) dan WRF (Ardie et al, 2012; Gustari et al, 2012), menunjukkan hasil yang variatif dan tidak konsisten yang umumnya disebabkan oleh buruknya kemampuan model numerik dalam melakukan simulasi terhadap siklus diurnal yang umumnya merupakan faktor dominan dari dinamika cuaca di wilayah tropis.

Studi yang bertujuan untuk menguji performa model WRF dalam melakukan prediksi cuaca pada saat kejadian banjir Jakarta tanggal 17 Januari 2013 diharapkan dapat menjadi referensi dan masukan yang berharga, baik untuk keperluan operasional, maupun untuk penelitian-penelitian selanjutnya tentang aplikasi model prediksi cuaca numerik dalam kaitannya dengan pengembangan sistem peringatan dini bencana, khususnya di wilayah benua maritim Indonesia.

\section{METODE}

\subsection{Konfigurasi Model}

Model WRF yang digunakan dalam studi ini adalah National Weather Service - Science and Training Research Center's (NWS-STRC) Environmental Modelling System (EMS), atau yang lebih dikenal sebagai WRF-EMS. Model ini merupakan suatu paket aplikasi prediksi cuaca numerik yang lengkap, serta mendukung sistem pemodelan NOAA (NEMS) dan WRF, dengan antarmuka yang sangat mudah digunakan. Pada studi ini, kami menggunakan Advanced Research WRF (ARW) sebagai dynamic solver, dengan domain bersarang (nested domains) yang terdiri dari domain induk (parent) dalam rentang 91,6 BT 151,27 BT dan 9,17 LU - 12,55 LS, dan domain anak (child) yang menjadi daerah studi dibatasi pada daerah dalam rentang 104 BT - 110 BT dan 4
LS - 8 LS. Resolusi spasial yang digunakan pada kedua domain model masing-masing $30 \mathrm{~km}$ dan 10 km (gambar 1).

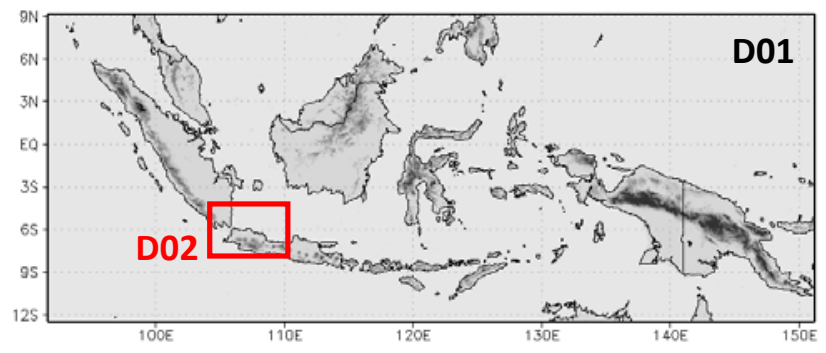

Gambar 1. Domain bersarang yang digunakan untuk simulasi model WRF, ditunjukkan dengan D01 untuk domain induk dan D02 untuk domain anak.

Kedua domain menggunakan konfigurasi dengan skema parameterisasi yang sama pada saat simulasi model. Skema Yonsei University (Hong et al, 2006) digunakan untuk parameterisasi Planetary Boundary Layer (PBL), sedangkan skema Noah Land Surface Model (Chen dan Dudhia, 2001) digunakan untuk parameterisasi fisis permukaan tanah. Untuk parameterisasi gelombang panjang dan pendek, kami menggunakan masing-masing skema Rapid Radiation Transfer Model (Mlawer et al, 1997) dan skema Dudhia (Dudhia, 1989), sedangkan skema Modified-Tiedtke (Zhang et al, 2011) dan skema Morrison (Morrison et al, 2005) masing-masing digunakan untuk parameterisasi kumulus dan mikrofisika. Rincian dari tiap skema parameterisasi yang digunakan pada studi ini dapat dilihat pada tabel 1 .

\subsection{Data}

Kami menggunakan data Global Forecast System (GFS) untuk tanggal 16 Januari 2013 pada cycle 12 UTC dengan resolusi spasial 0,5 derajat dan resolusi temporal 3 jam sebagai data inisiasi dan boundary model dengan lama simulasi 24 jam. Pemilihan data GFS pada cycle 12 UTC (19 WIB) dilakukan karena waktu tersebut adalah waktu yang terdekat untuk menggambarkan kondisi sebelum dan setelah banjir Jakarta pada tanggal 17 Januari 2013. Untuk verifikasi data curah hujan dari keluaran model, kami menggunakan data Global Satellite Mapping of Precipitaion (GSMaP) dari Japan Aerospace Exploration Agency (JAXA), dengan resolusi spasial 0,1 derajat dan resolusi temporal 1 jam. Kami juga menggunakan data reanalysis dari National Centers for Environmental Prediction National Oceanic and Atmospheric Administration (NCEP-NOAA) untuk verifikasi data vektor angin dari 
keluaran model WRF, dengan resolusi spasial 0,25 derajat dan resolusi temporal 1 hari.

Tabel 1. Skema parameterisasi yang digunakan untuk simulasi WRF.

\begin{tabular}{|c|c|}
\hline Opsi Fisis WRF & Skema Parameterisasi \\
\hline $\begin{array}{l}\text { Planetary Boundary } \\
\text { Layer }\end{array}$ & $\begin{array}{l}\text { Yonsei University Scheme } \\
\text { (Hong et al, 2006) }\end{array}$ \\
\hline Land Surface Physics & $\begin{array}{l}\text { Noah Land Surface Model } \\
\text { (Chen dan Dudhia, 2001) }\end{array}$ \\
\hline Longwave Radiation & $\begin{array}{l}\text { Rapid Radiation Transfer } \\
\text { Model (Mlawer et al, 1997) }\end{array}$ \\
\hline Shortwave Radiation & $\begin{array}{l}\text { Dudhia Scheme (Dudhia, } \\
\text { 1989) }\end{array}$ \\
\hline Cumulus & $\begin{array}{l}\text { Modified-Tiedtke (Zhang et } \\
\text { al, 2011) }\end{array}$ \\
\hline Microphysics & $\begin{array}{l}\text { Morrison (Morrison et al, } \\
2005 \text { ) }\end{array}$ \\
\hline
\end{tabular}

\subsection{Verifikasi Model}

Kami menggunakan metode verifikasi kualitatif dan kuantitatif kategorikal secara dikotomi dengan mencocokkan kejadian hujan dari data spasial keluaran model prediksi WRF dengan data observasi GSMaP pada setiap grid. Kejadian hujan dari prediksi yang benar pada suatu grid didefinisikan sebagai hit, sementara untuk kejadian tidak hujan yang diprediksi dengan benar, maka grid tersebut didefinisikan sebagai correct negative. $\mathrm{Di}$ sisi lain, kejadian hujan dan tidak hujan yang prediksinya salah masing-masing didefinisikan sebagai false alarm dan miss. Dengan menghitung nilai statistik berdasarkan jumlah hit, correct negative, false alarm dan miss dari tiap data, maka performa model dapat diketahui. Gustari et al (2012), mendemonstrasikan beberapa metode statistik yang dapat digunakan untuk menghitung performa model, antara lain: Akurasi (ACC), Threat Score atau Critical Success Index (CSI), Probability of Detection (POD) dan False Alarm Ratio (FAR).

ACC dihitung berdasarkan perbandingan jumlah hit dan correct negative dengan total grid pada suatu data spasial.

$$
A C C=\frac{\text { Hits }+ \text { Correct Negatives }}{\text { Jumlah total grid }}
$$

Nilai maksimum untuk ACC adalah 1 untuk prediksi sempurna dan minimum 0 untuk prediksi tanpa skill (100\% salah). Walaupun ACC umumnya digunakan untuk sebagai metode dasar untuk verifikasi data, namun nilai ACC kurang dapat menggambarkan kualitas model dalam melakukan prediksi terhadap lokasi objek, dalam hal ini hujan ekstrim. Sehingga diperlukan metode lainnya seperti CSI, POD dan FAR, yang didefinisikan sebagai :

$$
\begin{aligned}
C S I & =\frac{\text { Hits }}{\text { Hits }+ \text { Misses }+ \text { False Alarms }} \\
P O D & =\frac{\text { Hits }}{\text { Hits }+ \text { Misses }} \\
F A R & =\frac{\text { False Alarms }}{\text { Hits }+ \text { False Alarms }}
\end{aligned}
$$

Nilai CSI menggambarkan performa model dalam melakukan prediksi hujan dengan mengabaikan kejadian tidak hujan, sehingga hasilnya akan lebih objektif dibandingkan ACC. Nilai POD dan FAR masing-masing menggambarkan ketepatan model melakukan prediksi dilihat dari jumlah hasil deteksi dan false alarm yang dihasilkan. Nilai terbaik untuk CSI dan POD adalah 1 dan minimum 0 , sedangkan FAR memiliki nilai terbaik 0 dan minimum 1. Verifikasi dilakukan pada setiap data keluaran model selama 24 jam (tiap 1 jam) untuk memperoleh gambaran performa model secara numerik terhadap hasil observasi.

\section{HASIL DAN ANALISIS}

Gambar 2 menunjukkan perbandingan akumulasi curah hujan permukaan dan stream line di level $925 \mathrm{hPa}$ pada tanggal 17 Januari 2013, antara prediksi model WRF (domain D01) dengan hasil observasi GSMaP dan NCEP Reanalysis. Terlihat bahwa stream line dari keluaran WRF menunjukkan pola yang serupa dengan data observasi, terutama di wilayah Laut Cina Selatan, Selat Karimata dan Laut Jawa. Hal ini menunjukkan bahwa, secara kualitatif, WRF mampu memberikan prediksi arah dan kecepatan angin yang cukup akurat, terutama terhadap fenomena seruak dingin yang merupakan salah satu pemicu banjir Jakarta. WRF juga mampu memberikan prediksi pergerakan pusat tekanan rendah di sebelah barat daya Pulau Jawa (Samudera Hindia) yang menyebabkan terjadinya wilayah konvergensi di bagian barat Pulau Sumatera hingga bagian barat Pulau Jawa. Gambar 2 juga menunjukkan kejadian hujan dengan curah hujan di atas $90 \mathrm{~mm} /$ hari di Jawa bagian barat, berdasarkan hasil prediksi model dan data observasi. Perbedaan pola stream line pada pusat tekanan rendah di Samudera Hindia menyebabkan WRF kurang memberikan prediksi yang akurat terhadap posisi dari hujan ekstrim yang terjadi, di mana distribusi hujan lebih banyak terjadi di pesisir utara Jawa Barat apabila dibandingkan dengan data observasi yang menunjukkan hujan banyak terjadi hampir di seluruh Jawa Barat. 


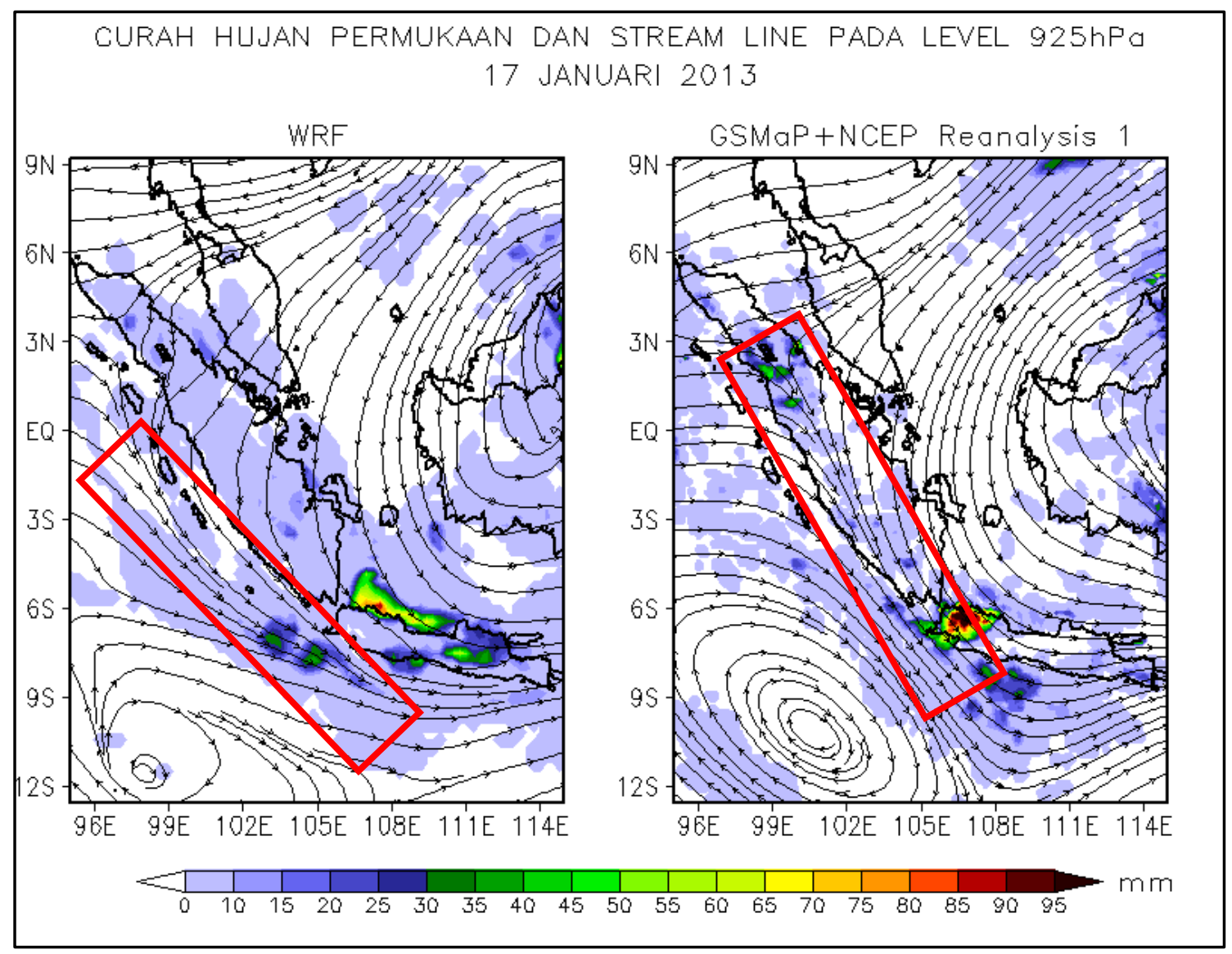

Gambar 2. Distribusi spasial dari akumulasi curah hujan dan pola stream line pada level $925 \mathrm{hPa}$ di wilayah Indonesia bagian barat pada tanggal 17 Januari 2013 berdasarkan hasil prediksi WRF (kiri) dan data observasi GSMaP + NCEP Reanalysis 1 (kanan). Daerah konvergensi pada kedua plot ditunjukkan dengan kotak berwarna merah.

Gambar 3 menampilkan distribusi spasial akumulasi 3-jam dari curah hujan di wilayah Jakarta dan sekitarnya pada hari yang sama, mulai dari pukul 00 LT sampai pukul 14 LT. Terlihat bahwa model WRF dengan tepat mampu memberikan prediksi awal terjadinya kejadian hujan ekstrim pada sekitar pukul 03 - 05 LT. Namun WRF memberikan prediksi yang tidak tepat terhadap durasi hujan yang terjadi, di mana hujan hanya diprediksi terjadi hingga pukul 05 LT, sedangkan data observasi menunjukkan hujan masih terjadi dalam intensitas tinggi hingga pukul 14 LT. Perbedaan intensitas dan durasi curah hujan ekstrim di wilayah Jakarta juga ditunjukkan pada gambar 4 .

Beberapa faktor yang menyebabkan tidak akuratnya prediksi WRF terhadap lokasi dan durasi hujan ekstrim di daerah Jakarta sekitarnya diduga adalah perbedaan posisi dan vortisitas dari pusat tekanan rendah yang terjadi di Samudera Hindia. Perbedaan ini menyebabkan posisi daerah konvergensi yang berada lebih di daerah barat pulau Sumatera dan Jawa, sehingga tubrukan (collision) antara massa udara konvergen dan pulau Jawa yang memicu hujan ekstrim tidak terjadi dengan intensif seperti halnya yang ditunjukkan dari data observasi.

Hasil verifikasi secara kuantitatif untuk keluaran model di domain D02 (Jawa Barat dan sekitarnya) pada tanggal 16-17 Januari 2013 ditunjukkan pada tabel 2. Terlihat bahwa WRF memiliki performa terbaik sekitar 9-16 jam setelah inisiasi model, atau sekitar pukul 02 LT hingga pukul 09 LT pada tanggal 17 Januari 2013. Hal ini ditunjukkan dari nilai CSI yang mencapai 0.32 dan POD yang mencapai 0.82. Pada periode waktu tersebut, WRF memiliki FAR minimum sebesar 0.66, di mana FAR yang rendah menunjukkan kemampuan WRF yang cukup baik dalam memberikan false alarm (prediksi hujan yang keliru). 


\section{AKUMULASI CURAH HUJAN UNTUK WILAYAH JAKARTA DAN SEKITARNYA 17 JANUARI 2013}
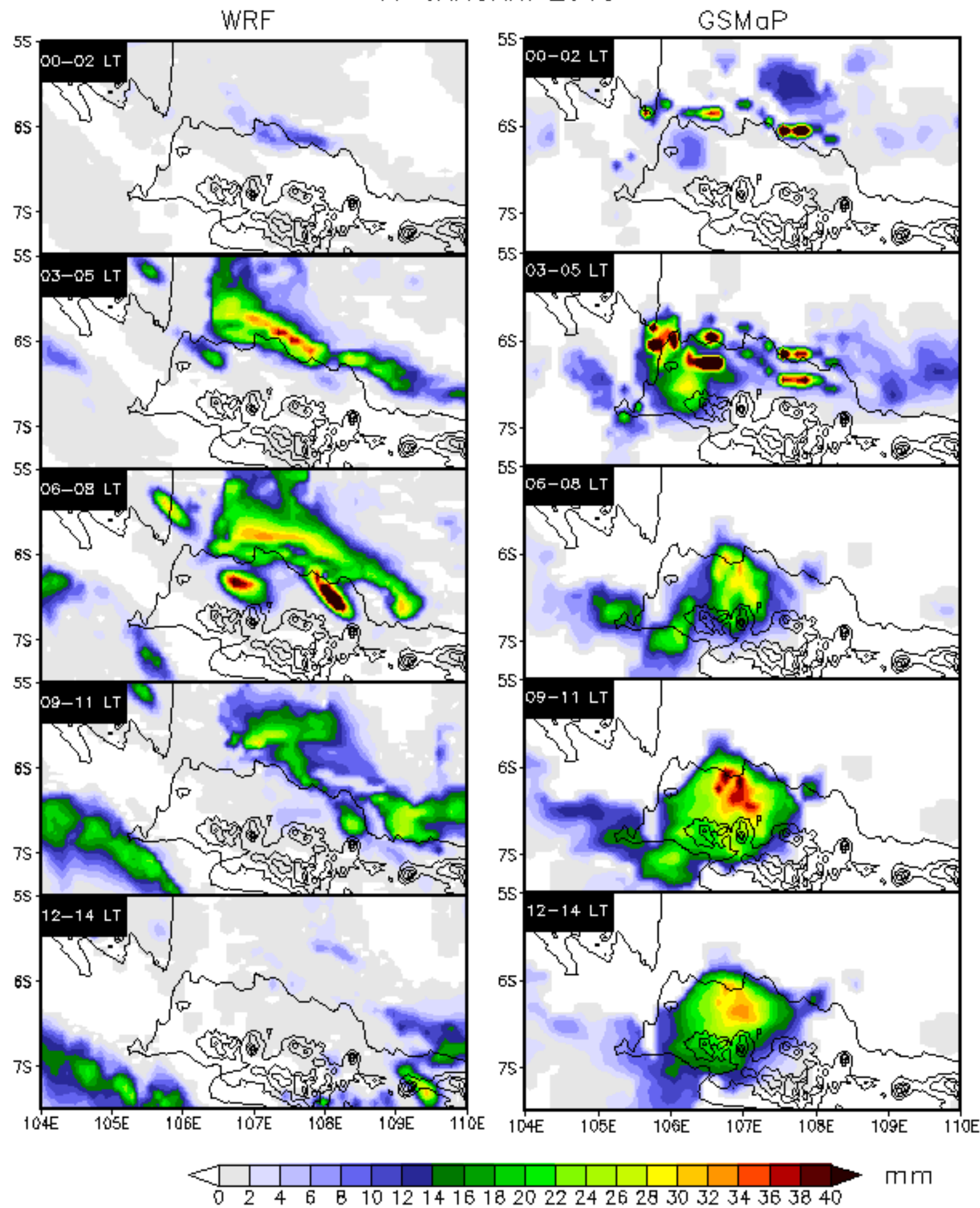

Gambar 3. Akumulasi curah hujan per 3-jam pada pukul 00 - 14 LT (WIB) untuk wilayah Jakarta dan sekitarnya pada tanggal 17 Januari 2013, berdasarkan hasil prediksi WRF (panel kiri) dan data observasi GSMaP (panel kanan). 


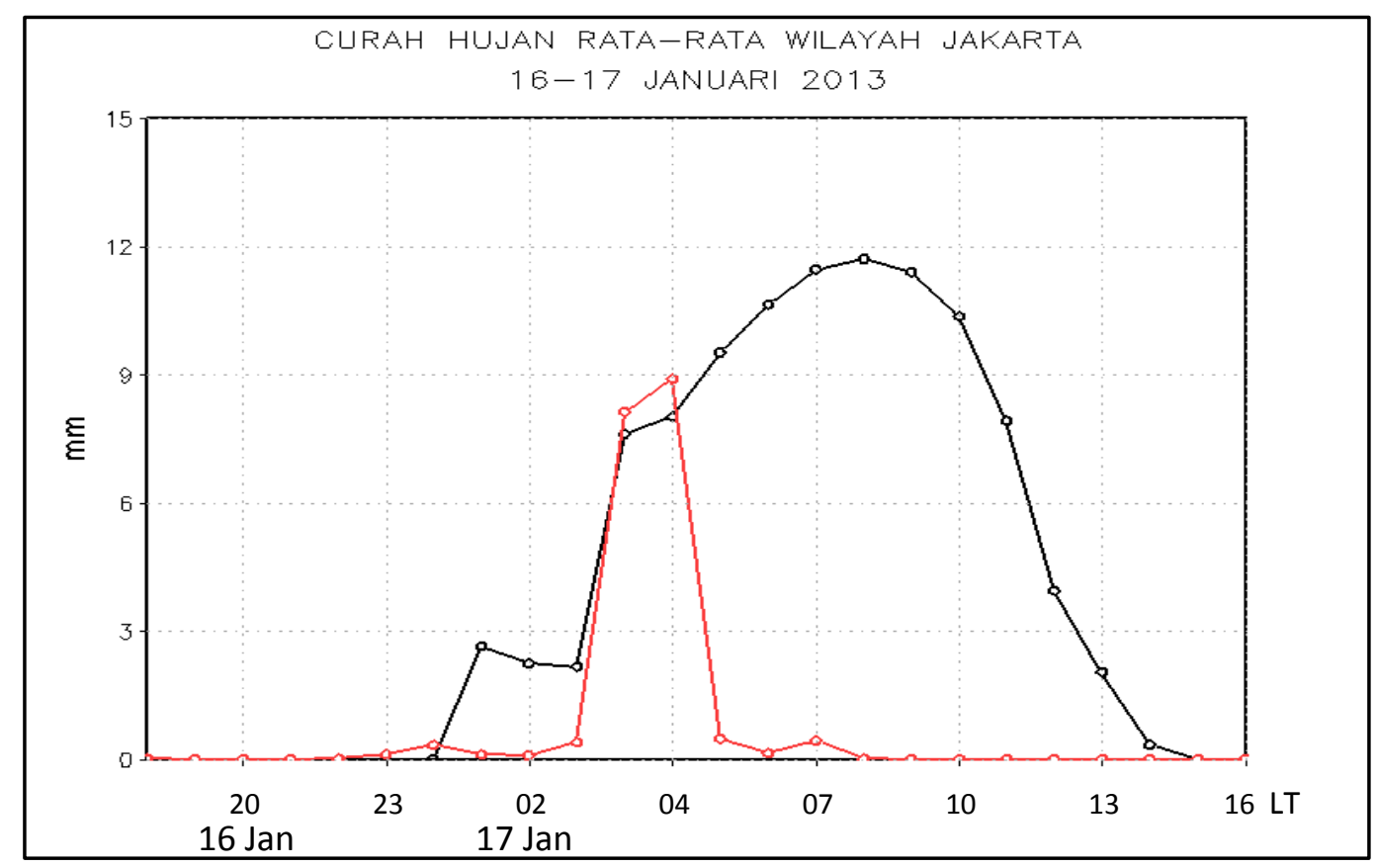

Gambar 4. Grafik time series curah hujan wilayah untuk wilayah Jakarta $(106,72-106,96$ BT dan $6.1-6.3$ LS) pada tanggal 16-17 Januari 2013, berdasarkan hasil prediksi WRF (merah) dan data observasi GSMaP (hitam).

Tabel 2. Hasil verifikasi kuantitatif hasil prediksi WRF dengan data observasi GSMaP pada tanggal 16-17 Januari 2013. Bagian yang dicetak tebal menunjukkan nilai terbaik untuk tiap metode statistik.

\begin{tabular}{cccccc}
\hline Step & Jam & ACC & CSI & POD & FAR \\
\hline 1 & 18 & $\mathbf{0 . 8 8}$ & 0.03 & 0.08 & 0.96 \\
2 & 19 & 0.76 & 0.03 & 0.22 & 0.96 \\
3 & 20 & 0.66 & 0.06 & 0.26 & 0.92 \\
4 & 21 & 0.62 & 0.08 & 0.41 & 0.91 \\
5 & 22 & 0.58 & 0.12 & 0.63 & 0.87 \\
6 & 23 & 0.54 & 0.12 & 0.69 & 0.88 \\
7 & 00 & 0.48 & 0.22 & 0.56 & 0.73 \\
8 & 01 & 0.53 & 0.26 & 0.62 & 0.69 \\
9 & 02 & 0.53 & 0.28 & 0.68 & 0.67 \\
10 & 03 & 0.53 & 0.29 & 0.72 & 0.67 \\
11 & 04 & 0.49 & 0.24 & 0.70 & 0.73 \\
12 & 05 & 0.51 & 0.28 & 0.77 & 0.70 \\
13 & 06 & 0.50 & 0.30 & 0.81 & 0.68 \\
14 & 07 & 0.49 & 0.32 & $\mathbf{0 . 8 2}$ & $\mathbf{0 . 6 6}$ \\
15 & 08 & 0.47 & 0.30 & 0.76 & 0.67 \\
16 & 09 & 0.45 & 0.28 & 0.73 & 0.68 \\
17 & 10 & 0.41 & 0.24 & 0.60 & 0.72 \\
18 & 11 & 0.43 & 0.24 & 0.59 & 0.71 \\
19 & 12 & 0.42 & 0.22 & 0.52 & 0.73 \\
20 & 13 & 0.41 & 0.14 & 0.40 & 0.82 \\
21 & 14 & 0.33 & 0.08 & 0.27 & 0.90 \\
22 & 15 & 0.32 & 0.08 & 0.30 & 0.89 \\
23 & 16 & 0.46 & 0.03 & 0.67 & 0.97 \\
24 & 17 & 0.47 & 0.05 & 0.87 & 0.95 \\
\hline Mean & & 0.51 & 0.18 & 0.57 & 0.8 \\
\hline & & & & &
\end{tabular}

Di sisi lain, apabila ditinjau secara keseluruhan, kemampuan WRF untuk memberikan prediksi lokasi dan kejadian hujan ekstrim selama 24 jam masih tidak konsisten dengan nilai rata-rata CSI 0,18, ACC 0,51, POD 0,57 dan FAR 0,8. Hal ini dipicu oleh buruknya performa WRF pada waktuwaktu awal dan akhir simulasi.

Performa WRF yang meningkat dalam 9-16 jam setelah waktu inisiasi model menunjukkan bahwa aplikasi waktu spin-up pada simulasi perlu dipertimbangkan dalam meningkatkan kemampuan prediksi model numerik untuk keperluan peringatan dini. Umumnya waktu spin-up yang digunakan untuk simulasi adalah 6-12 jam dari cycle yang digunakan sebagai data inisiasi. Hasil verifikasi juga menunjukkan bahwa model WRF cenderung lebih banyak menghasilkan false alarm dibandingkan hits (prediksi hujan yang benar).

Salah satu faktor yang mempengaruhi performa model numerik adalah pemilihan skema parameterisasi yang digunakan untuk simulasi. Oleh karena itu, studi lebih lanjut dengan menggunakan berbagai skema parameterisasi perlu dilakukan untuk meningkatkan kemampuan model prediksi cuaca numerik untuk peringatan dini bencana di wilayah benua maritim Indonesia. 


\section{KESIMPULAN}

Pada studi ini, kami melakukan simulasi WRF untuk pemodelan atmosfer pada kejadian banjir Jakarta tanggal 17 Januari 2013. Hasil verifikasi model secara kualitatif dan kuantitatif menunjukkan bahwa WRF mampu memberikan prediksi waktu awal kejadian hujan ekstrim secara tepat, serta mampu menggambarkan pola angin yang disebabkan oleh fenomena seruak dingin dengan baik. Performa terbaik WRF terlihat dalam waktu 916 jam setelah waktu inisiasi yang masing-masing ditunjukkan oleh nilai CSI, POD dan FAR yang relatif baik. Namun, apabila diamati secara keseluruhan, performa WRF cenderung tidak konsisten selama 24-jam akibat buruknya prediksi pada waktu awal dan akhir simulasi model.

Performa model yang tidak konsisten dalam memberikan prediksi lokasi dan durasi hujan ekstrim menunjukkan perlunya studi lebih lanjut tentang aplikasi WRF untuk peringatan dini bencana di wilayah benua maritim Indonesia, terutama daerah Jakarta dan sekitarnya yang kerap mengalami bencana banjir pada puncak musim hujan setiap tahun. Perbaikan performa model numerik umumnya dapat dilakukan dengan pemilihan skema parameterisasi yang tepat untuk menggambarkan kondisi atmosfer pada waktu prediksi, maupun perbaikan pada data masukan model dengan asimilasi menggunakan berbagai data pengamatan. Dengan demikian, diharapkan performa model numerik, terutama WRF, dapat ditingkatkan untuk kebutuhan riset maupun keperluan prediksi operasional di Indonesia di masa yang akan datang.

\section{REFERENSI}

Ardie, W. A., K. S. Sow, F. T. Tangang, A. G. Hussing, M. Mahmud and L. Juneng, 2012: The performance of different cumulus parameterization schemes in simulating the 2006/2007 southern peninsular Malaysia heavy rainfall episodes. J. Earth Syst. Sci., 121(2), 317-327.

Chang, C. P., Z. Wang, J. McBride and C. H. Liu, 2005: Annual cycle of southeast Asia Maritime continent rainfall and the asymetric monsoon transition. J. Climate, 18, 287-301.

Chen, F., and J. Dudhia, 2001: Coupling an advanced land surface-hydrology model with the Penn state-NCAR MM5 modeling system. Part I: Model implementation and sensitivity. Mon Weather Rev., 129, 569-585.

Dudhia, J., 1989: Numerical study on convection observed during the winter monsoon experiment using a mesoscale two- dimensional model. J. Atmos. Sci., 46, 30773107.

Gustari, I., T. W. Hadi, S. Hadi and F. Renggono, 2012: On the accuracy of operational daily rainfall forecasts over Jabodetabek: A comparison with raw WRF-model output. Jurnal Meteorologi dan Geofisika, 13(02), 119-130.

Hong, S.-Y., Y. Noh, J. Dudhia, 2006: A new vertical diffusion package with an explicit treatment of entrainment process. Mon Weather Rev., 134, 2318-2341.

Mlawer, E. J., S. J. Taubman, P. D. Brown, M. J. lacono, and S. A. Clough, 1997: Radiative transfer for inhomogeneous atmospheres: RRTM, a validated correlated-k model for the longwave. J. Geophys. Res., 102, 16663-16682.

Morrison, H., J. A. Curry, M. D. Shupe, and P. Zuidema, 2005: A new double-moment microphysics parameterization for application in cloud and climate models. Part I: Description. J. Atmos. Sci., 62, 1665-1677.

Salimun, E., F. T. Tangang and L. Juneng, 2010: Simulation of heavy precipitation episode over eastern Peninsular Malaysia using MM5: Sensitivity to cumulus parameterization schemes. Meteorol. Atmos. Phys., 107, 33-49.

Skamarock, W. C., J. B. Klemp, J. Dudhia, D. O. Gill, D. M. Barker, G. D. Michael, X. Y. Huang, W. Wang and J. G. Powers, 2008: A description of the Advanced Research WRF Version 3. NCAR Tech Notes-475+STR.

Sow, K. S., L. Juneng, F. T. Tangang, A. G. Hussin and M. Mahmud, 2010: Numerical simulation of a severe late afternoon thunderstorm over Peninsular Malaysia. Atmos. Res., doi: 10.1016/j.atmosres.2010.10.014.

Tiedtke, M., 1989: A comprehensive mass flux scheme for cumulus parameterization in large-scale models. Mon. Weather Rev., 117, 1779-1800.

Wu, P., A. A. Arbain, S. Mori, J.-I. Hamada, M. Hattori, F. Syamsudin and M. D. Yamanaka, 2013: The effects of an active phase of the Madden-Julian Oscillation on the extreme precipitation event over Western Java Island in January 2013. SOLA, 9, 79-83.

Zhang, C.-X, Y.-Q. Wang and K. Hamilton, 2011: Improved representation of boundary layer clouds over the Southeast Pacific in ARWWRF using a modified Tiedtke cumulus parameterization scheme. Mon. Weather Rev., 139, 3489-3513. 